\title{
PERCEPTIONS, BELIEFS, AND ATTITUDES OF FIRST YEAR THIRD- LEVEL STUDENTS: AN EMPIRICAL STUDY OF PORTUGUESE, RUSSIAN, POLISH, FINNISH, AND IRISH STUDENTS
}

\author{
K. Brown ${ }^{1}$, A.P. Lopes ${ }^{2}$, F. Soares ${ }^{2}$, V. Larionova ${ }^{3}$, A. Cellmer ${ }^{4}$, J. Hurme ${ }^{5}$ \\ ${ }^{1}$ Letterkenny Institute of Technology (IRELAND) \\ ${ }^{2}$ Polytechnic of Porto (PORTUGAL) \\ ${ }^{3}$ Ural Federal University (RUSSIAN FEDERATION) \\ ${ }^{4}$ Politechnika Koszalinska (POLAND) \\ ${ }^{5}$ Oulu University of Applied Sciences (FINLAND)
}

\begin{abstract}
The contemporary skillset of undergraduates includes a degree of sophistication in the application of ICT within their daily lives as well as within the higher education environment. The assumption of the student as a digital native, with the ability to cognitively process information in an ICT focused educational environment, is omnipresent in higher education. It has been suggested this assumption does not aid learning and adds an additional burden on the student.
\end{abstract}

This study investigated whether experiences and perceptions, of mathematics and online assessment, are common to students studying in different countries and their respective higher education systems.

The purpose of the investigation was to determine what issues influence the attitudes of students in the application of ICT for the online assessment of mathematics in the first year of undergraduate programmes.

The investigation was conducted online by means of a quantitative questionnaire, consisting of 16 survey items, using Google Forms to self-selecting students $(n=374)$ across several academic disciplines including engineering, business studies, media, and tourism. The survey was delivered in English to the majority students and translated to Russian for the Russian students to enable each group to reply in their own native language. The questionnaire design utilized a 6-point Likert scale where students were asked to express their experiences and perceptions of mathematics and online assessment in their chosen programme of study. The data was exported to IBM SPSSv24 and regression analyses were conducted to ascertain possible associations and relationships between the two student groups in the case study.

The results of the investigation reveal some peculiar features and the respective investigation outcomes of the investigation will be utilized in the design of learner-centered assessments and shared with international partners.

Keywords: Freshman experience, First-Year student experience, Self-efficacy, Expectancy, Online Assessment, Mathematics.

\section{INTRODUCTION}

Successful entry into first year study at a Higher Education Institution (HEI) is considered to be the beginning of a period of transition and adjustment for many students [1]. With the exception of nonstandard entry students, the majority will have just completed second-level education where the environment is, strictly defined, controlled, and attendance is compulsory. Third level study flips the role of responsibility onto the student and this may cause stress and difficulty in the transition to selfdirected learning and autonomy promotion.

Assessment of mathematics using ICT is increasingly appearing in many programmes [2] however, the extent of resultant negative behavioural attributes [3] does not appear to be considered as a primary concern within the design of ICT enabled programmes [4]. A smooth transition to third level depends on recognition by HEls that issues pertaining to digital competence are handled in a supportive manner to help the students [5] in their own sense of readiness to become self-directed learners. 
This study considers some of the issues related to students entering and completing the first year of study in a HEl. The socio-cognitive environment, prior experiences, confidence, self-esteem and ability to self-regulate [6] may be considered by some to be barriers to progress [7]. Instructional delivery and associated assessment may be viewed as one such barrier and, in many cases, the educators consider this beyond their sphere of influence and scope. Effective design of the mathematics curriculum must consider strategies that respond to learners "fears" and any perceived educationrelated barriers.

One of the barriers considered is the "maths problem" $[8,9,10,11,12]$ as characterized by a lack of basic conceptual skills, poor understanding, and inability to solve problems. In addition to this barrier is the additional hurdle of using ICT for assessment and the associated variation in students' skills [13].

The research has been grounded in a social-cognitive framework expectancy [14] and self-efficacy $[15,16]$. Students in Ireland and Finland were engaged in a longitudinal study over a period of three years and that study was extended to include similar students in three further countries to determine if the perceptions of confidence, expectancy and, barriers are representative and, eventually, distinct.

\subsection{Objectives}

The objective of the research is the improvement of the educational experiences of first year students as they study mathematics modules within various disciplines. Thus, the aims of the study are:

- To investigate the levels of prior engagement of online testing prior to third level.

- To investigate the perceptions of barriers to engagement that learners may have using online assessment systems.

- To investigate the levels of confidence and expectancy of first year students.

\section{METHODOLOGY}

\subsection{Participants}

A convenience sample of 374 first-year undergraduate engineering, tourism and media students from HEls in Ireland, Poland, Finland, Russia and Portugal completed an online questionnaire. The research was conducted and bounded within the shared mathematics domain of the first year of the programmes in the five countries. The questionnaire measured self-reported confidence, expectancy, preparedness for study and perceived barriers to study at the end of the second semester. The questionnaire was conducted in English in Ireland, also in Poland, Finland, and Portugal to avoid misguiding differences in translated terms, and translated to Russian for the Russian students.

The methodology was explained to the students, after participation consent was sought, to ensure that all students were aware that any decision to participate or withdraw would not have any negative impact on them. Data was collected in week eight of the second semester by means of an anonymized questionnaire, containing two dichotomous questions, and fifteen six-point Likert scale questions. All responses were coded for analysis and processing using the Statistical Package for the Social sciences software (SPSS).

The students were self-selecting based on convenience of students to the researchers.

\section{RESULTS}

A total of 374 students participated in the study questionnaire (male, $n=236$; female, $n=138$ ). To consider the questions on Expectancy and Confidence, the analysis was conducted between countries and for gender using IBM SPSSv24. As already stated, five countries participated in the study: Ireland, Poland, Finland, Russia, and Portugal. 


\subsection{Gender}

\subsubsection{Prior Experience of Online Testing}

A logistic regression test was conducted to determine if there were differences in reported experiences, according to gender, of online testing prior to study at third level. The regression model was statistically significant, $X^{2}(1)=4.208, p=0.04$. Males had 1.538 times higher odds of having experience of online testing prior to third level than females.

$$
\begin{array}{ccccccccc} 
& & & & & & & \multicolumn{3}{c}{95 \% \text { Confidence }} \\
\text { Gender } & 0.430 & \text { SE } & \text { Wald } X^{2} & \text { df } & \text { sig } & \exp (B) & \text { lower } & \text { Upper } \\
& 0.210 & 4.208 & 1 & 0.040 & 1.538 & 1.019 & 2.320
\end{array}
$$

\subsubsection{Confidence}

An independent-samples t-test was conducted to determine if there were differences in confidence levels between males and females. There were no outliers in the data, as assessed by inspection of boxplot. Confidence scores for males were not normally distributed, as assessed by Shapiro-Wilk's test $(p<0.05)$, however examination of the $Q-Q$ plots reveals straight-line data. Skewness and Kurtosis values were very similar to the female distribution. The confidence scores for females were normally distributed, assessed by Shapiro-Wilk's test $(p>0.05)$. There was homogeneity of variances, assessed by Levene's test for equality of variances $(p=0.545)$. Female participants were slightly more confident $(M=3.93, S D=0.84)$ than male participants $(M=3.82, S D=0.86)$, but not statistically significantly different, $\mathrm{M}=0.11,95 \% \mathrm{Cl}[0.07$ to 0.29$], \mathrm{t}(372)=1.175, \mathrm{p}=0.241, \mathrm{~d}=0.126$.

\subsubsection{Expectancy}

An independent-samples t-test was conducted to determine if there were differences in expectancy between males and females. There were no outliers in the data, as assessed by inspection of boxplot. Confidence scores for males and females were not normally distributed, as assessed by ShapiroWilk's test $(p<0.05)$, however examination of the $Q-Q$ plots reveals straight-line data, Skewness and Kurtosis values were also very similar. Due to robustness of the t-test it was decided to continue with the analysis. There was homogeneity of variances, assessed by Levene's test for equality of variances $(p=0.494)$. Female participants reported higher levels of expectancy $(M=3.97, S D=0.48)$ than male participants $(M=3.82, S D=0.51)$, statistically significantly different, $M=0.14,95 \% C l[0.04$ to 0.24$]$, $\mathrm{t}(372)=2.696, \mathrm{p}=0.007, \mathrm{~d}=0.289$.

\subsection{Country}

The questions of differences relating to confidence and expectancy of students in each participating country were tested using one-way ANOVA. The rationale for this test is that there are 5 categorical groups and no relationship between observations in each group of the independent variable. Each group has different participants and cannot influence another group. Participants were all in the first year of study at higher education. No hypothesis about the differences between the groups has been used. Therefore post-hoc testing was conducted using a GLM procedure. The mismatched group sizes were handled using a Tukey-Kramer test instead of a standard Tukey test (requiring groups of same size). The group sizes were:

$$
\begin{array}{lll}
\text { Ireland } n=50 & \text { Poland } n=68 & \text { Portugal } n=103 \\
\text { Finland } n=97 & \text { Russia } n=56 &
\end{array}
$$

\subsubsection{Confidence}

A one-way Welch ANOVA was conducted to determine if the self-reported confidence levels of students was different for participating country. There were no outliers, assessed by boxplot; data was normally distributed for each group, as assessed by Shapiro-Wilk test $(p>0.05)$; but there was heterogeneity of variances, as assessed by Levene's test of homogeneity of variances $(p=0.011)$. Confidence score varied among the groups: Ireland $(M=3.850, S D=0.989)$, Poland $(M=3.790$, $S D=0.684)$, Finland $(M=3.838, S D=0.832)$, Russia $(M=3.946, S D=0.764)$, and Portugal $(M=3.891$, $S D=0.951)$. The differences between the groups were not statistically significant $(p>0.05)$, Welch's $F(5,186.450)=0.367, p=0.871$. The country means for confidence are displayed in figure 1 . 


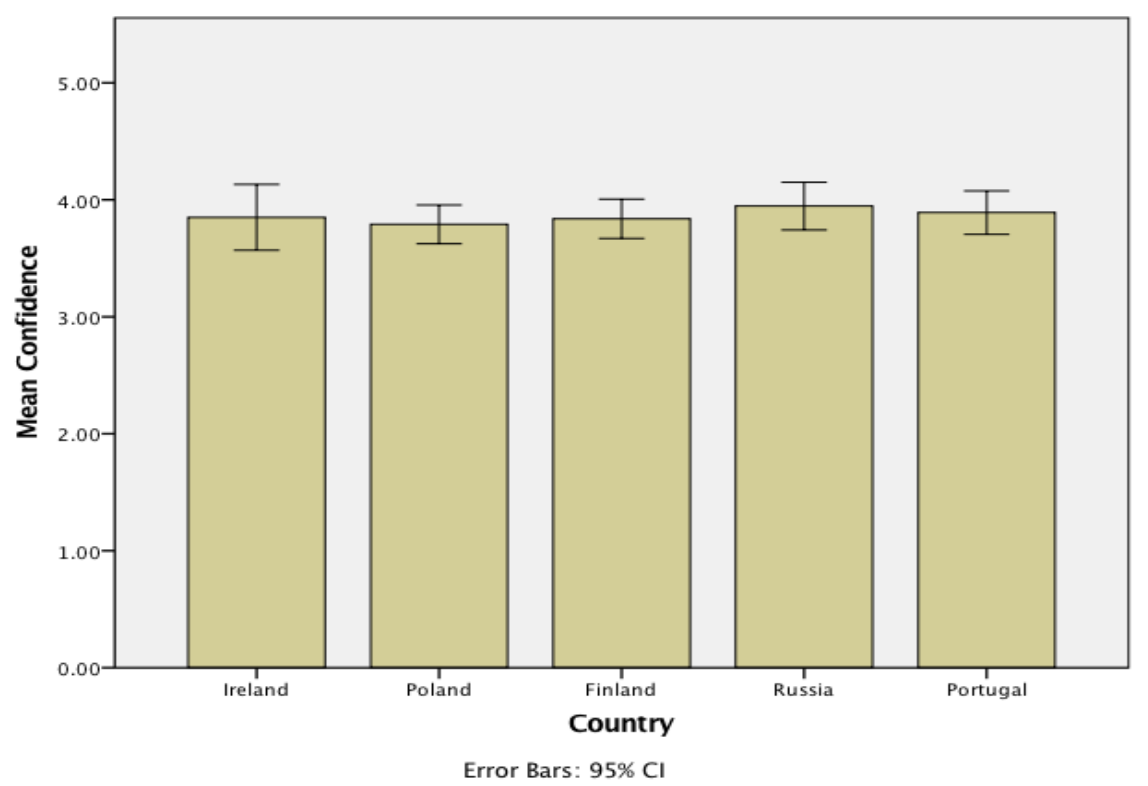

Figure 1. Mean Confidence level per country.

\subsubsection{Expectancy}

A one-way ANOVA was conducted to determine if the expectancy was different for the groups of students in the different countries. There were no significant outliers, as assessed by boxplot; data was normally distributed for each group, assessed by Shapiro-Wilk test $(p>0.05)$; and there was homogeneity of variances, assessed by Levene's test of homogeneity of variances $(p=0.07)$. Expectancy was statistically significantly different between certain student groups, $F(5,340)=6.580$, $p<0.0005, \omega^{2}=0.06$.

Expectancy score increased from Polish students $9 M=3.63, S D=0.55)$ to Russian students $(M=4.07$, $\mathrm{SD}=0.42)$. Tukey post hoc analysis revealed that the mean increase from Poland to Russia $(0.44,95 \%$ $\mathrm{CI}[0.19,0.69]$ was statistically significant $(p<0.0005)$.

Expectancy score increased from Polish students $[M=3.63, S D=0.55)$ to Portuguese students $(M=3.97, S D=0.49)$. Tukey post hoc analysis revealed that the mean increase from Poland to Portugal $(0.35,95 \% \mathrm{Cl}[0.13 .0 .57]$, which was statistically significant $(p<0.0005)$.

No other group differences were statistically significant. The country means for expectancy are displayed in figure 2 .

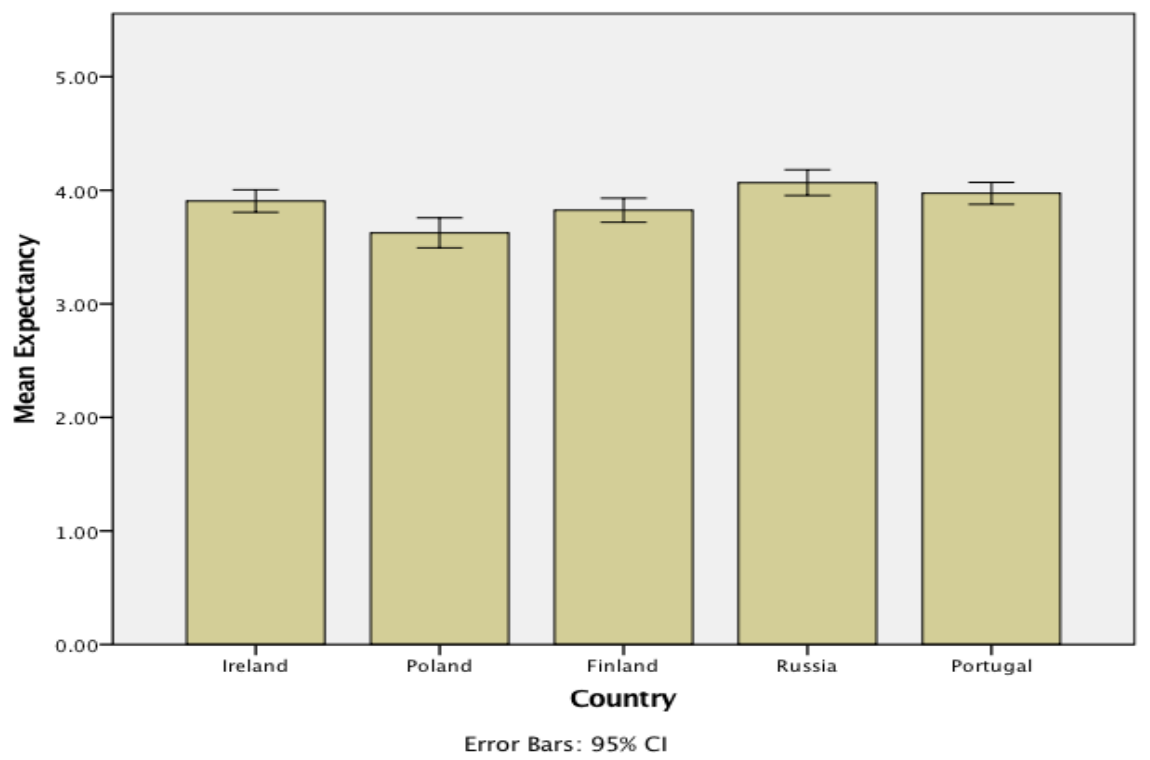

Figure 2. Mean Expectancy level per country. 


\subsubsection{Prior Experience of Online Testing}

A logistic regression test was conducted to determine if there were differences in reported experiences, according to country, of online testing prior to study at third level. The regression model was statistically significant for all comparisons involving Ireland. Irish students had lower odds of having experience of online testing prior to third level than students in Poland, Finland, Russia, and Portugal. Irish students were:

- $0.155(95 \% \mathrm{Cl}, 0.066$ to 0.361$)$ times that of Polish students, a statistically significant effect, $X^{2}(5)=18.590, p<0.05$.

- $0.148(95 \% \mathrm{Cl}, 0.066$ to 0.330$)$ times that of Finnish students, a statistically significant effect, $\mathrm{X}^{2}(5)=21.647, \mathrm{p}<0.05$.

- $0.061(95 \% \mathrm{Cl}, 0.023$ to 0.159$)$ times that of Russian students, a statistically significant effect, $X^{2}(5)=32.807, p<0.05$.

- $0.179(95 \% \mathrm{Cl}, 0.081$ to 0.397$)$ times that of Portuguese students, a statistically significant effect, $X^{2}(5)=17.926, p<0.05$.

\section{CONCLUSIONS}

The study was based on three issues: prior online testing experience, perceptions of barriers, and confidence and expectancy. All participants were voluntary and self-selecting and engaged using Google forms using an anonymous questionnaire. Demographic information is not available and comparisons cannot be made regarding student profiles.

The most significant result in relation to experience of online testing prior to third level provides a lens for the Irish students. The tests were statistically significant for all comparisons between countries indicating that further research is required to determine if this is representative for Ireland as a whole or is particular to the participating higher education institution in this instance. The tests for confidence between the participating countries revealed no statistically significant differences. Of note in relation to expectancy are the lower scores of the Polish students when compared with Russian and Portuguese students. Further research may reveal why such statistically significant differences exist.

Gender analyses were considered in relation to the total sample and not per country. Significant differences exist between both genders but not in all issues addressed by the study. Worthy of note is the statistically significant higher expectancy score of females compared to males.

This study represents the findings from a desire to gather a reflection of the first year experience and to determine if major differences exist between groups of students in similar higher education institutions in different countries. The students' sense of belonging, engagement within, and comprehension of assessment, in programmes where mathematics is a major element is crucial to their continued motivation and satisfaction. Programme designers must remain cognizant of the variation in ICT skills base of the students on entry to third level and the expectations of those students. As programmes become more internationally entwined it is necessary that a solid understanding of the student base entering the programmes is developed to address the needs of the students. The results will feed into the design processes of the first year mathematics programme to improve the student experience.

\section{REFERENCES}

[1] Pennington, C.R., Bates, E.A., Kaye, L.K. \& Bolam, L.T., (2017). Transitioning in higher education: an exploration of psychological and contextual factors affecting student satisfaction, Journal of Further and Higher Education, DOI 10.1080/0309877X.2017.1302563

[2] Jordan, S., (2013). E-assessment: Past, present and future, New Directions, 9(1), pp.87-106.

[3] Tempel, T. \& Neumann, R., (2014). Stereotype threat, test anxiety, and mathematics performance, Social Psychology of Education, 17(3), pp. 491-501.

[4] Brown, K., Hurme, J., \& Lally, V., (2016). Realties in rhetoric of online testing: a higher education case study, European Conference on Educational Research, UCD, Dublin. 
[5] Van Rooij, E., Jansen, E., \& Van de Grift, W., (2016). Ready for University? Profiling Secondary School Students on University Readiness, European Conference on Educational Research, UCD, Dublin.

[6] Van Dinther, M., Dochy, F., \& Segers, M., (2011). Factors affecting students' self-efficacy in higher education, Educational Research Review, 6 pp.95-108.

[7] Artino, A.R. \& Jones, K.D., (2012). Exploring the complex relations between achievement emotions and self-regulated learning behaviors in online learning, The Internet and Higher Education, 15(3), pp. 170-5.

[8] Goto, S.T., \& Martin, C., (2009). Psychology of success: overcoming barriers to pursuing further education, The Journal of Continuing Higher Education, 57(1) pp.10-21.

[9] Alves, M., Rodrigues, C.S., Rocha, A.C., \& Coutinho, C., (2016). Self-efficacy, mathematics anxiety and perceived importance: an empirical study with Portuguese engineering students, European Journal of Engineering Education, 41 pp.105-121.

[10] Prendergast, M., \& Treacy, P., (2017). Curriculum reform in Irish secondary schools - a focus on algebra, Journal of Curriculum Studies, DOI: 10.1080/00220272.2017.1313315

[11] Treacy, P., Faulkner, F., \& Prendergast, M., (2016). Analysing the correlation between secondary mathematics curriculum change and trends in beginning undergraduates' performance of basic mathematical skills in Ireland, Irish Educational Studies, 35(4) pp.381-401.

[12] Kinnari, H., (2010). A study of mathematics proficiency, $1^{\text {st }}$ Intl workshop on maths and ICT: Education, Research and Applications, Bucharest, pp.35-39.

[13] Heerwegh, D., \& De Wit, K., (2016). Exploring the self-reported ICT skill levels of undergraduate science students, Journal of Information Technology Education: Research, 15 pp.19-47.

[14] Vroom, V. H., Deci, E.L., (1970). Management and Motivation. Penguin 1983 (first published 1970).

[15] Bandura, A., (1977). Self-efficacy: Toward a Unifying Theory of Behavioral Change, Psychological Review, 84(2), pp. 191-215.

[16] Artino, A.R., (2012). Academic self-efficacy: from educational theory to instructional practice, Perspectives on medical education, 1(2), pp. 76-85. 